Japan. J. Med. Sci. Biol., 41, 1-13, 1988.

\title{
AN OUTBREAK OF SALMONELLOSIS IN NEWLY IMPORTED CYNOMOLGUS MONKEYS
}

\author{
Masao TAKASAKA, Ayako KOHNO1, Ippei SAKAKIBARA, \\ Hayato NARITA1 and Shigeo HONJO
}

Tsukuba Primate Center for Medical Science, National Institute of Health, and 1The Corporation for Production and Research of Laboratory Primates, 1 Hachimandai, Tsukuba-shi, Ibaragi 305, Japan

(Received March 1, 1988. Accepted June 8, 1988)

SUMMARY: Serious salmonellosis occurred in groups of cynomolgus monkeys newly imported into Tsukuba Primate Center for Medical Science from the Philippines in 1985. During the quarantine period, Salmonella typhimurium (29 strains) and $S$. stanley (1 strain) were isolated from 30 of 130 imported monkeys. Twenty-eight of the 30 infected monkeys excreted mainly watery diarrhea, and occasionally bloody mucous stool. Seven of the 28 clinical cases infected with $S$. typhimurium resulted in death or in moribund state. In both the small and large intestines of autopsied monkeys, acute inflammatory changes were observed.

\section{INTRODUCTION}

Many investigators have published papers concerning the isolation of Salmonella from nonhuman primates (1-12). Salmonella organisms are occasionally associated with overt disease symptoms in nonhuman primates $(2,4,6,12)$, but most animals infected are symptomless $(3,7,10)$. Therefore, we had not thought that Salmonella organisms were such important pathogens at our laboratory primates quarantine facility.

高阪精夫・榊原一兵・本庄重男 (国立予防衛生研究所筑波医学実験用霊長類センター 茨城県つくば市八幡台 1 )

鴻野あや子·成田勇人 (社団法人予防衛生協会＼cjkstart茨城県つくば市八幡台 1 ) 
According to our epidemiological survey for the infection with pathogenic bacteria of wild cynomolgus monkeys imported from Southeast Asian countries from 1982 through 1984, Salmonella infection rate averaged about 1\% on arrival at Tsukuba Primate Center for Medical Science (TPC). During the quarantine period of at least 9 weeks, only one of the Salmonella-positive animals excreted bloody mucous stool and died of enteritis, while the other animals were asymptomatic and Salmonella organisms disappeared spontaneously from their gastrointestinal tracts.

Recently, we encountered an outbreak of serious salmonellosis among cynomolgus monkeys newly imported from the Philippines into TPC quarantine facility. The present report deals with the bacteriological, serological, clinical and pathological findings.

\section{MATERIALS AND METHODS}

Animals: From September through October, 1985, a total of 130 cynomolgus monkeys (Macaca fascicularis) in three different groups were imported from the Philippines into TPC. Groups 1, 2 and 3 were consisted of 50, 50 and 30 animals, respectively. The animals in each group were divided into six to 10 transportation crates containing five animals each. It took about one day for transportation of animals from the Philippines to TPC by air. The methods of care and management of newly arrived animals were the same as described previously (13).

Bacteriological test procedure: Fecal specimens collected by the rectal swab or freshly evacuated feces were used for the isolation of Shigella and Salmonella. Specimens taken from dead and euthanized monkeys were also used for bacterial isolation. Immediately after collection, the specimens were cultured on both Salmonella-Shigella (SS) agar and desoxycholate-hydrogen sulfide-lactose (DHL) agar. Most of the specimens, except blood, were inoculated also into enrichment broth (Hajna's tetrathionate broth or Selenite broth). Blood samples were inoculated into another enrichment broth: Vacutainer Culture Tube containing supplemented peptone broth (Becton-Dickinson \& Co.). After incubation at $37 \mathrm{C}$ for 18 or $48 \mathrm{hr}$, each enrichment culture was placed on DHL agar or Trypticase soy agar (BBL) with $5 \%$ horse defibrinated blood. The procedures for isolating and identifying Shigella and Salmonella were based on the ordinary diagnostic bacteriological techniques. The determination of serovars of Salmonella isolated was carried out by use of the Salmonella diagnostic antisera (Difco and Denka Seiken Co., Ltd., Tokyo).

Serological test: All the sera taken were stored at $-20 \mathrm{C}$ until examined. The sera were inactivated at $56 \mathrm{C}$ for $30 \mathrm{~min}$ and diluted with saline twofold serially 
from 1:10 to 1:1,280. The antibody level against somatic (O) antigen of Salmonella was examined by the $O$ agglutination test (Widal test) according to the method described by Sakazaki (14).

Drug-sensitivity test: Thirty isolated Salmonella strains were tested for the sensitivity to 12 kinds of antibacterial drugs, namely, ampicillin, erythromycin, chloramphenicol, tetracycline, kanamycin, dihydrostreptomycin, cephalothin, cefazolin, colistin, sulfisoxazole, nalidixic acid and rifampicin. The drug sensitivity was tested by the agar dilution method for rifampicin, and the disc method for dihydrostreptomycin using Showa Disk (Showa Yakuhin Kako Co., Ltd., Tokyo) containing $50 \mathrm{\mu g} /$ disc of dihydrostreptomycin and Tridisk (Eiken Chemical, Co., Ltd., Tokyo) of three-graded concentrations of the other 10 drugs. In rifampicin, strains which could not grow in concentration of $50 \mu \mathrm{gg} / \mathrm{ml}$ were determined to be sensitive. In the other 11 drugs, slightly sensitive strains were determined to be resistant.

Histopathological observations: In total, seven monkeys were autopsied. Their internal organs, including the alimentary tracts, were examined for microscopic lesions by the ordinary histological method.

\section{RESULTS}

\section{Infection Rate of Salmonella in Cynomolgus Monkeys during the Quarantine Period}

Out of 130 cynomolgus monkeys, 30 (23.1\%) were infected with Salmonella during the quarantine period of 9 weeks (Table I). One monkey in Group 1, one in Group 2 and five in Group 3 harbored Salmonella on arrival at TPC. Thereafter, the infection rate of Salmonella in each group increased to $18-28 \%$ by the end of the quarantine period. Shigella was not isolated from any monkey during the quarantine period.

Twenty-nine of 30 Salmonella isolates were serologically identified as $S$. typhimurium and the other one as S. stanley.

\section{Clinical Findings of Monkeys Infected with Salmonella}

The main symptom in overt clinical cases was diarrhea. As shown in Table I, 28 (27 S. typhimurium-positive and one S. stanley-positive animals) of the 30 infected monkeys showed mainly watery diarrhea, and occasionally bloody mucous stool accompanied with anorexia and depression. The remaining two monkeys infected with $S$. typhimurium showed no sign of disease and the bacilli disappeared 


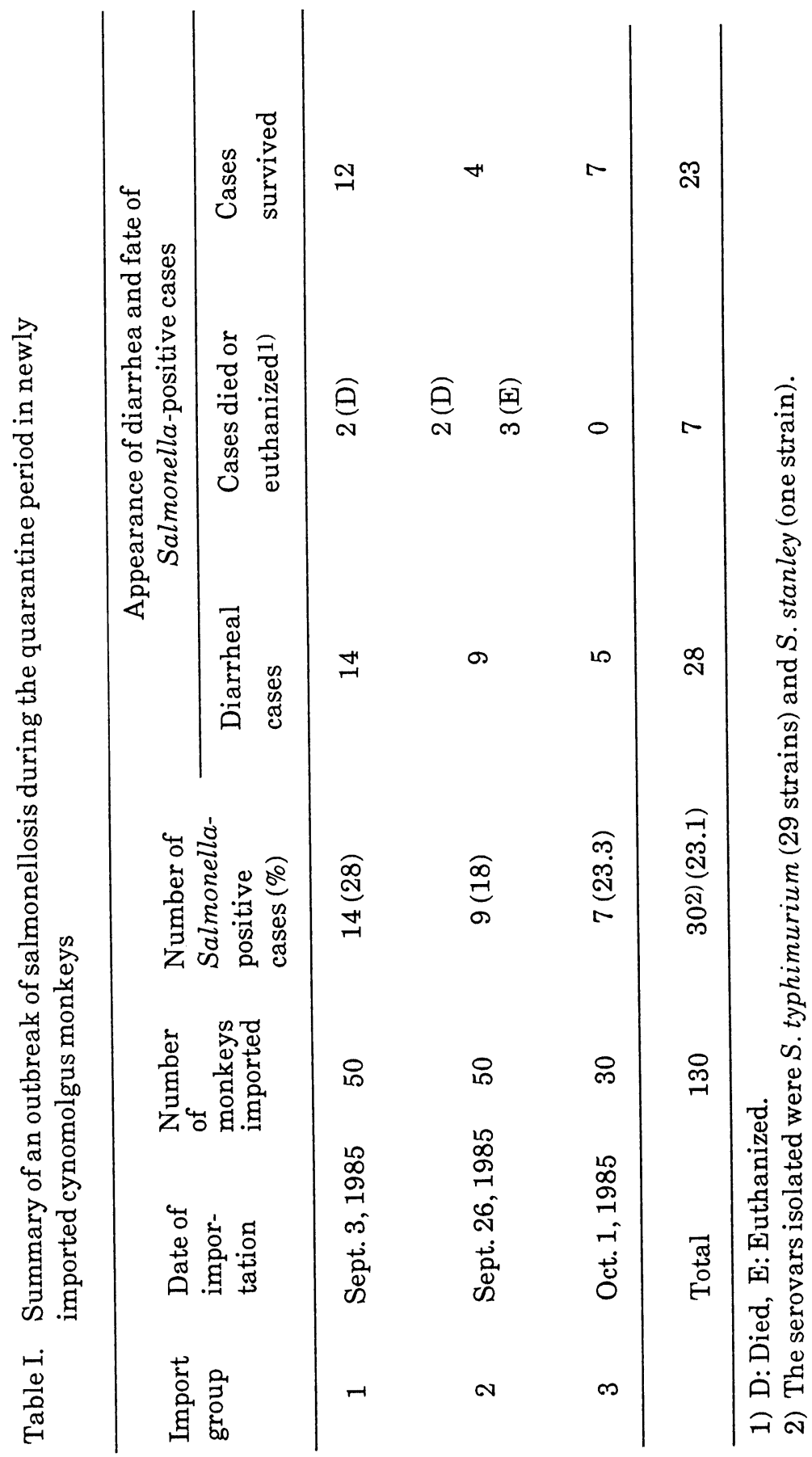


spontaneously. Fourteen (50\%) of these 28 diarrheal cases began to excrete diarrheal stool within 7 days after their arrival at TPC. In general, diarrhea continued for a few days to about one month.

Four cases died 4, 9, 14 and 21 days after the onset of diarrhea. The other three were euthanized 4, 8 and 25 days after the onset of diarrhea, because they became moribund (Table I). All of the seven monkeys were infected with $S$. typhimurium.

The typical course of diarrheal cases was as follows: No. 12 of Group 1 harbored S. typhimurium in normal stool on arrival and began to excrete diarrheal stool one day after arrival. The diarrhea continued for 22 days until death in spite of the treatment with colistin. S. typhimurium was re-isolated 3 and 15 days after the onset of diarrhea. The same serovar of Salmonella was isolated from the stomach, the small intestine, the large intestine and the bile of the autopsied monkey (Table II).

No. 82 of Group 2 began to excrete diarrheal stool 3 days after arrival. The diarrhea continued for 26 days despite the administration of cefazolin, colistin and rifampicin. The monkey became moribund and was euthanized 25 days after the onset of disease. S. typhimurium was isolated from the large intestine and the intestinal lymph node at autopsy as well as from stool 2, 9 and 19 days after the onset of disease (Table II). The $\mathrm{O}$ agglutinin titer of this monkey was below 1:10 on arrival and rose to 1:160 at autopsy 25 days after the onset of disease (Table III).

\section{Pathological and Bacteriological Findings in Autopsied Cases}

Congestion and edema were observed in the mucous membrane of the ileum of monkey No. 41, and in the cecum or the colon of monkeys Nos. 12, 68 and 82. Besides the intestinal lesion, the mesenteric lymph nodes of monkey No. 68 were swollen. Microscopically, adhesion of the villus in the small intestine was observed. Degeneration and desquamation of the epithelium of mucous membrane were observed in the small and large intestine. The lamina propria and the submucosa were edematous and congestive. The lamina propria was infiltrated with small round cells and histiocytes, but rarely with polymorphonuclear leukocytes. In some cases, micro-abscess was observed within the crypts (Fig. 1). No pathological lesion that was judged to be associated with Salmonella infection was found in any other internal organs examined.

Isolation of $S$. typhimurium from various organs of autopsied monkeys is shown in Table II. The bacilli were isolated from the gastrointestinal tracts in 


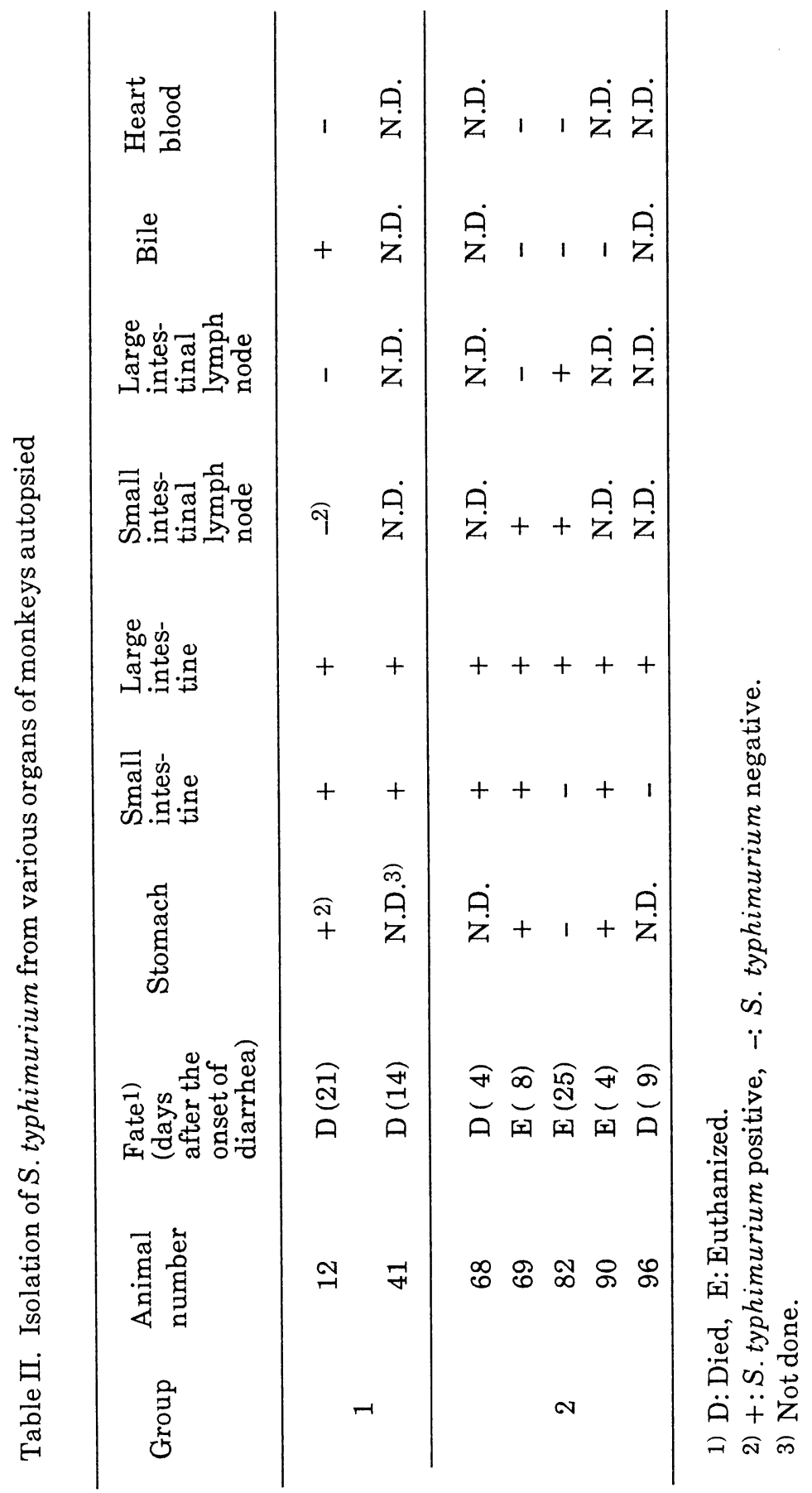




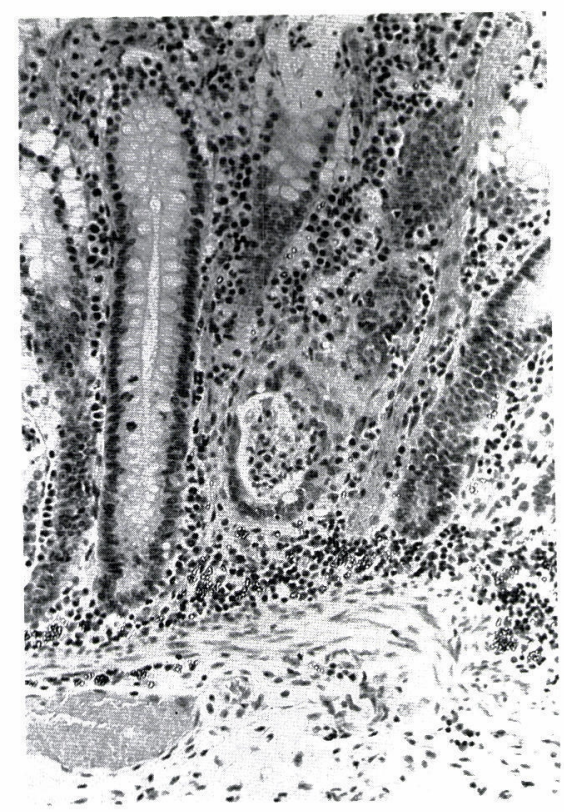

Fig. 1. The colon of monkey No. 82 euthanized 25 days after onset of diarrhea. The epithelial tissue is markedly degenerated and desquamated. Lamina propria is infiltrated with small round cells and histiocytes, and congestive. Micro-abscess in crypt is observed. Submucosa is congestive and edematous. Original magnification $\times 100$.

all cases examined and from the intestinal lymph nodes in two of three cases examined. In one of four cases examined, the bacilli were isolated also from the bile. However, no Salmonella was found in heart blood of three cases examined.

\section{O Agglutination Antibody in Salmonella-positive Monkeys}

As shown in Table III, out of 30 Salmonella-positive monkeys, 24 infected with S. typhimurium and one infected with S. stanley were examined for $\mathrm{O}$ agglutination antibody against the homologous antigen.

In all monkeys infected with S. typhimurium, O agglutinin titers were 1:20 or lower on arrival at TPC. Of the 24 monkeys, 22 excreted diarrheal stools but the remaining two showed no clinical signs during the quarantine period. In all diarrheal cases except two (Nos. 126 and 130), the titer increased to 1:20 - 1:160 7 to 48 days after the onset of diarrhea. On the other hand, the titers of two nondiarrheal cases (Nos. 101 and 121), that were below 1:10 on arrival, did not show any noticeable change throughout the quarantine period. 


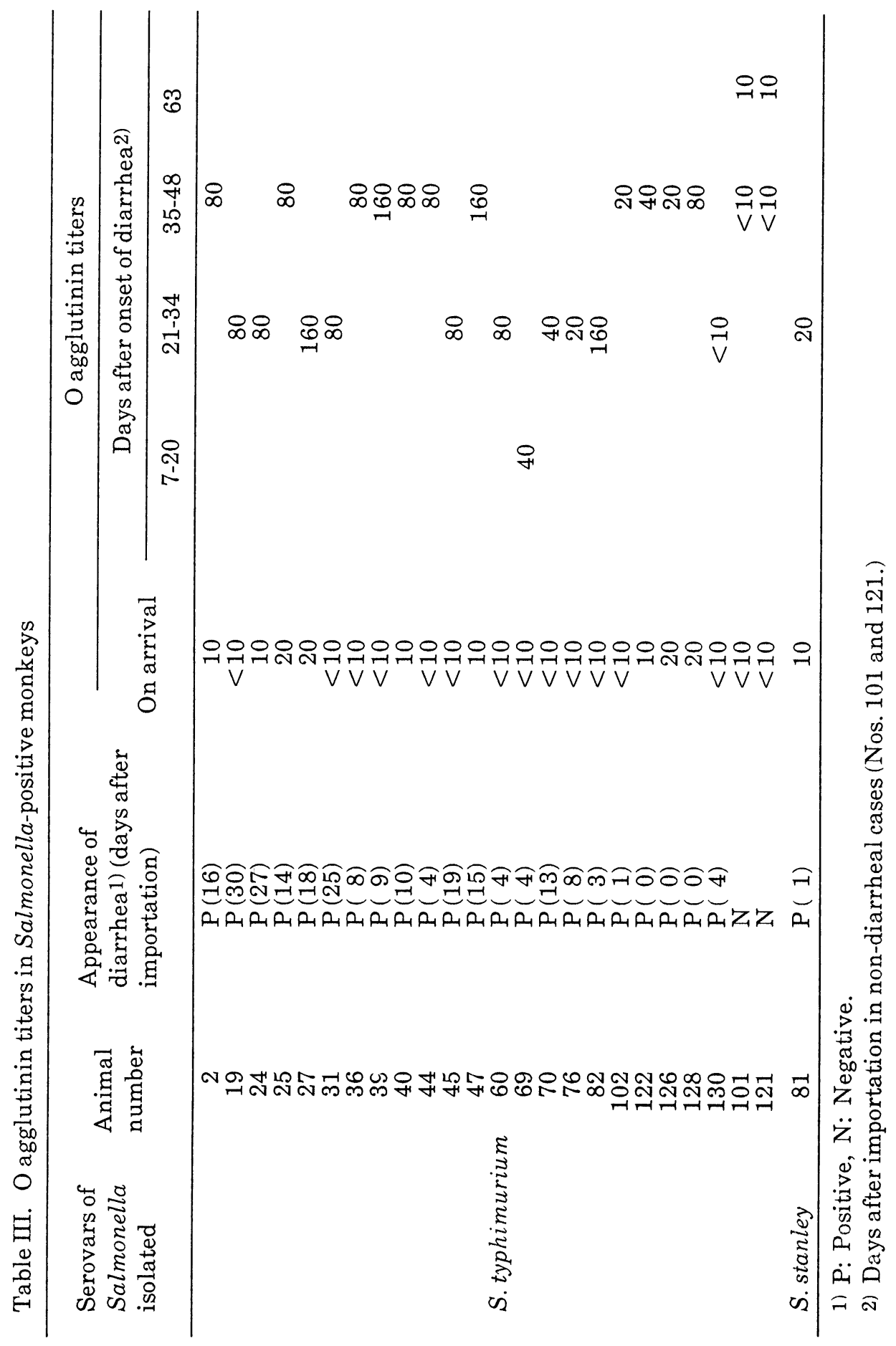


Table IV. Drug sensitivity of 30 Salmonella strains isolated from cynomolgus monkeys

\begin{tabular}{lc}
\hline Drug & $\begin{array}{c}\text { Per cent of sensitive } \\
\text { strains }\end{array}$ \\
\hline Ampicillin & 6.7 \\
Erythromycin & 0 \\
Chloramphenicol & 0 \\
Tetracycline & 0 \\
Kanamycin & 0 \\
Dihydrostreptomycin & 6.7 \\
Cephalothin & 100 \\
Cefazolin & 100 \\
Colistin & 100 \\
Sulfisoxazole & 3.3 \\
Nalidixic acid & 100 \\
Rifampicin & 96.7 \\
\hline
\end{tabular}

In one monkey (No. 81) infected with $S$. stanley, the titer was 1:10 on arrival and showed only twofold rise 34 days after the onset of diarrhea.

\section{Drug Sensitivity of 30 Salmonella Strains Isolated}

As shown in Table IV, all the strains tested were highly sensitive to cephalothin, cefazolin, colistin, and nalidixic acid. Twenty-nine of the 30 strains were sensitive to 25 or $50 \mu \mathrm{g} / \mathrm{ml}$ and the remaining one was resistant to $100 \mu \mathrm{g} / \mathrm{ml}$ of rifampicin. However, most strains were resistant to ampicillin, erythromycin, chloramphenicol, tetracycline, kanamycin, dihydrostreptomycin and sulfisoxazole.

On the basis of the results described above, 21 diarrheal monkeys received cefazolin, colistin, rifampicin and ampicillin singly or in combination. Eighteen of these 21 monkeys recovered from diarrhea but the remaining three died or became moribund. Of the seven diarrheal monkeys which received no antibiotics, three recovered spontaneously from diarrhea and the other four died or became moribund. In spite of the administration of antibiotics, Salmonella was found in feces for a long period in some monkeys which recovered from diarrhea. 


\section{DISCUSSION}

The present bacteriological, serological, clinical and pathological findings clearly demonstrated an outbreak of salmonellosis in cynomolgus monkeys newly imported from the Philippines.

Although little is known as yet about the pathogenicity of many different serovars of Salmonella isolated from nonhuman primates, Fiennes et al. (15) described that $S$. typhimurium, S. stanley and $S$. enteritidis are the most pathogenic for nonhuman primates. The present results, showing that the serovars of Salmonella isolated from diarrheal monkeys were $S$. typhimurium and S. stanley, seemed to confirm the description by Fiennes et al (15).

Lapin and Yokovleva (16) reported that the pathological lesions of catarrheal enteritis in monkeys that died of salmonellosis were primarily found in the small intestine with lesser involvement of the large intestine and the stomach. On the other hand, Kent et al. (17) stated that the early lesion in rhesus monkeys administered intragastrically with $S$. typhimurium was more predominant in the large intestine rather than in the small intestine. In the present salmonellosis caused by $S$. typhimurium, the pathological lesions involved both the small and large intestines.

A comparison of the clinical and pathological findings between simian salmonellosis and simian shigellosis seems very interesting and important from the viewpoint of nonhuman primate models of human diseases as well as of nonhuman primate medicine. In the present simian salmonellosis, mainly watery diarrhea and occasionally bloody mucous stool were seen, but in simian shigellosis, mainly bloody mucous stool was observed $(18,19)$. With regard to salmonellosis, pathological lesions were found both in the small and large intestines, while in shigellosis the lesions were confined to the large intestine (20). In addition, the degree of the inflammatory reaction in the large intestine in salmonellosis was milder than that in shigellosis.

Little information is available concerning the therapeutic effect of antibiotics on simian salmonellosis. Schneider et al. (1) stated that none of the broadspectrum antibiotics such as terramycin and chloramphenicol had a significant effect on Salmonella infection in macaque monkeys. Generally, antibiotic therapy for salmonellosis in humans, even when the causative organisms are demonstrated to be sensitive in vitro, does not shorten or otherwise alter the clinical course of illness. Dixon (21) and Aserkoff and Bennett (22) reported that antibiotic treatment in acute Salmonella gastroenteritis did not shorten the period of symptomless excretion of Salmonella organisms, but prolonged it. In the present 
study, antibiotics that had been judged effective by the in vitro test proved to be effective for the reduction of mortality, but not effective for the complete elimination of Salmonella carriers. Since monkeys with salmonellosis were given different regimens of antibiotic therapy, the exact information pertaining to the choice of antibiotics, the specific dosage, and the duration of treatment was not necessarily obtained in the present study. Therefore, further investigations are required to clarify these points.

As to the source of Salmonella infection in the present monkeys, we consider that they had been infected with the organisms at the monkey-dealer's compound in the Philippines, because the organisms were isolated from stool specimens taken on arrival at TPC in all three different shipments.

According to Lapin and Yakovleva (16), the fact that salmonellosis rarely occurs in nonhuman primates, in spite of their crowded feeding conditions and the comparatively high incidence of Salmonella carriers, suggests that the nonhuman primate animals are highly resistant to Salmonella infection, and the disease does develop if the resistance is lowered. We think that the present outbreak of salmonellosis must have been related to lowered resistance that may have resulted from stressful situations caused by the transportation from the country of origin to Japan and the rapid changes in feeding conditions at TPC.

Bohnhoff and Miller (23) reported that oral administration of streptomycin increased the susceptibility of mice to infection with the streptomycin-resistant strain of S. enteritidis. In addition, Miller and Bohnhoff (24) considered that the increased susceptibility was related chiefly to the elimination of Bacteroides species from the intestine. Many salmonellosis cases in the present study had been given chloramphenicol or ampicillin before the onset of clinical symptoms for either prophylactic treatment of pneumonia or therapy for trauma. It can be considered, therefore, that the antibiotic treatment may have been a provoking factor for the present occurrence of salmonellosis.

We have never experienced such a serious outbreak of salmonellosis in cynomolgus monkeys as the present one. Therefore, we think that more appropriate attention should be paid to Salmonella as well as Shigella infection in newly imported cynomolgus monkeys. 


\section{ACKNOWLEDGEMENT}

The authors thank Drs. Eiichi Miyagawa and Hajime Minato, Feed Microbiology Laboratory, National Institute of Animal Health, for their help in serological typing of Salmonella strains isolated.

\section{REFERENCES}

1. Schneider, N. J., Prather, E. C., Lewis, A. L., Scatterday, J. E. and Hardy, A. V. (1960): Ann. N. Y. Acad. Sci., 85, 935-941.

2. Deinhardt, F., Holmes, A. W., Devine, J. and Deinhardt, J. (1967): Lab. Anim. Care, 17, 48-70.

3. Dood, R. C., May, B. D. and Kawatomari, T. (1969): J. Bacteriol., 97, 10481055.

4. Rowe, B. (1969): Lab. Anim. Handbooks, 4, 63-75.

5 Kourany, M. and Porter, J. A., Jr. (1969): Lab. Anim. Care, 19, 336-341.

6. Kourany, M. and Rossan, R. N. (1971): Lab. Anim. Sci., 21, 412-414.

7. Ford, A. C., Speltie, T. M. and Hendriks, W. D. H. (1973): Lab. Anim. Sci., 23, 649-652.

8. Aikawa, T., Kameyama, K., Karashimada, T., Ishige, M., Noro, S., Sato, N. and Sakurada, N. (1975): Report of The Hokkaido Institute of Public Health, No. 25, 49-52 (in Japanese).

9. Sakamoto, O. and Isozaki, A. (1980): Yobou Igaku J., No. 144, 14-19 (in Japanese).

10. Tanaka, Y. and Katsube, Y. (1981): Japan. J. Vet. Sci., 43, 787-789.

11. Tribe, G. W. and Fleming, M. P. (1983): Lab. Anim., 17, 65-69.

12. Klumpp, S. A., Weaver, D. S., Jerome, C. P. and Jokinen, M. P. (1986): Vet. Pathol., 23, 190-197.

13. Honjo, S. (1985): J. Med. Primatol., 14, 75-89.

14. Sakazaki, R. (1966): In K. Yanagisawa (ed.), Biseibutu Kensa Hikkei, p. 677688. Japan Public Health Assoc., Tokyo (in Japanese).

15. Fiennes, R. N. T-W-, Lapin, B. A., Dzhikidze, E. K. and Yakovleva, L. A. (1972): In R. N.T-W-Fiennes (ed.), Pathology of Simian Primates, Part I, p. 671-710. S. Karger AG, Basel.

16. Lapin, B. A. and Yakovleva, L. A. (1963): Comparative Pathology in Monkeys. Charles C Thomas Publisher, Springfield, Illinois, USA. 272p.

17. Kent, T. H., Formal, S. B. and LaBrec, E. H. (1966): Arch. Pathol., 82, 272279.

18. Honjo, S., Takasaka, M., Fujiwara, T., Nakagawa, M., Andoo, K., Ogawa, H., Takahashi, R. and Imaizumi, K. (1964): Japan. J. Med. Sci. Biol., 17, $307-$ 319. 
19. Takasaka, M., Morota, S., Kasono, T., Abe, M. and Honjo, S. (1973): Exptl. Anim., 22, 227-236 (in Japanese).

20. Ogawa, H., Takahashi, R., Honjo, S., Takasaka, M., Fujiwara, T., Ando, K., Nakagawa, M., Muto, T. and Imaizumi, K. (1964): Japan. J. Med. Sci. Biol., 17, 321-332.

21. Dixon, J. M. S. (1965): Brit. Med. J., 2, 1343-1345.

22. Aserkoff, B. and Bennett, J. V. (1969): New Engl. J. Med., 18, 636-640.

23. Bohnhoff, M. and Miller, C. P. (1962): J. Infect. Dis., 111, 117-127.

24. Miller, C. P. and Bohnhoff, M. (1963): J. Infect. Dis., 113, 59-66. 